\title{
Parental drinking in Australia: does the age of children in the home matter?
}

Running head: Parental drinking in Australia

Jacqueline A Bowden ${ }^{1,2}$, Paul Delfabbro', Robin Room ${ }^{3,4}$, Caroline Miller, ${ }^{2,5}$, Carlene Wilson $^{6,7,8}$

1. School of Psychology, University of Adelaide, Adelaide, Australia

2. South Australian Health and Medical Research Institute, Adelaide, Australia

3. Centre for Alcohol Policy Research, La Trobe University, Melbourne, Australia

4. Centre for Social Research on Alcohol and Drugs, Department of Public Health Sciences, Stockholm University, Stockholm, Sweden

5. School of Public Health, University of Adelaide, Adelaide, Australia

6. School of Medicine, Flinders Centre for Innovation in Cancer, Flinders University, Adelaide, Australia

7. Olivia Newton John Cancer Wellness and Research Centre and School of Psychology and Public Health, La Trobe University, Melbourne, Australia

8. School of Psychology and Public Health, La Trobe University, Melbourne, Australia.

\section{Conflict of interest None to declare}

Jacqueline A Bowden MPH, Manager, Population Health Research, Paul Delfabbro PhD, Professor, Robin Room PhD, Professor, Caroline Miller PhD, Director, Population Health Research, Carlene Wilson PhD, Professor of Psycho-oncology.

Corresponding Author: Mrs Jacqueline Bowden

South Australian Health and Medical Research Institute

North Terrace

Adelaide, SA 5000, Australia.

Tel: +61881284095

Email: jacqueline.bowden@sahmri.com

This is the author manuscript accepted for publication and has undergone full peer review but has not been through the copyediting, typesetting, pagination and proofreading process, which may lead to differences between this version and the Version of Record. Please cite this article as doi: 10.1111/dar.12875

This article is protected by copyright. All rights reserved. 


\begin{abstract}
Introduction and Aims: Parental role modelling of alcohol use is known to influence alcohol consumption in adolescence and in later life. This study aimed to assess relationships between parental status, child age and alcohol consumption, which have not been well documented. Design and Methods: Data were sourced from the 2013 Australian National Drug Strategy Household Survey. Analyses were conducted for 25-55 year olds ( $\mathrm{n}=11,591$ ) by parental status, gender, and age of youngest child in the household, controlling for sociodemographic factors. Results: Parents were less likely than non-parents to exceed alcohol guideline for long-term use (18.2\% vs $24.2 \%)$ and short-term risk: at least weekly ( $14.2 \% \mathrm{vs}$ $21.2 \%)$; and at least monthly (27.5\% vs $35.9 \%)$. Fathers were just as likely to exceed the guidelines for lifetime risk as other men, but those with children aged 0-2, were less likely to exceed the guideline for short-term risk. Women were least likely to exceed the guideline for long-term risk if they had children aged 0-2, 6-11 or 15 years and over, or the guideline for short-term risk, if they had children aged $0-2$, or 15 years and over in the household. Parents were more likely to report drinking in the home. Discussion and Conclusion: Parents were less likely to exceed alcohol guidelines than non-parents, especially mothers whose youngest child was an infant or in high school or older. Consistent with population rates in men, fathers were more likely to exceed alcohol guidelines than mothers, and this excess consumption warrants public health attention.
\end{abstract}

Keywords: Alcohol, parents, consumption. 


\section{INTRODUCTION}

Australians are relatively high consumers of alcohol per capita [1], with drinking a feature of Australian culture. The latest national survey found that $77 \%$ of people aged 14 years or over had consumed alcohol in the past 12 months, with $26 \%$ drinking alcohol at levels that placed them at risk of short-term harm from alcohol-related injury and $17 \%$ at levels placing them at risk of lifetime harm from alcohol-related disease and injury (refer to the methods section for a full definition) [2]. Furthermore, a recent study found that $73 \%$ of the community believe that Australia has a problem with alcohol abuse [3].

Much of the alcohol drunk in Australia is consumed within the home - the drinker's or someone else's (79\%) [4]. Bandura's Social Learning Theory postulates that children and adolescents learn about what is acceptable behaviour through observation and interacting with those to whom they are closest to [5]. Parental role modelling has been found to be an important factor determining when and how children initiate drinking. Specifically, US studies and a systematic review found that observation of parental alcohol use increases the likelihood of earlier initiation [6-9] and studies from the US, Finland, UK, Netherlands and a systematic review have found that parental consumption affects the amount of later adolescent alcohol consumption [9-13]. Early initiation leads to risky alcohol use; the leading cause of death and disability in 15-24 year olds globally [14]. There is also growing evidence that early age of initiation (i.e. before 15 years) is a risk factor for developing alcohol-related problems in later life [15]. Ameliorating the problems that flow from early, and often unsupervised, alcohol initiation requires further analysis of parental alcohol consumption patterns and levels.

There has been limited consideration of parental alcohol consumption in Australia. One population survey reported that parents were less likely to drink at risky levels compared to those without dependent children. The study estimated that between 710,000 and 1.4 million Australian parents drink at short- or long-term risky levels [16]. Data from 2013 revealed that a sizeable proportion of Australian parents consume alcohol. Parents were more likely to report being moderate drinkers than non-parents, less likely to report being abstainers, and less likely to report being risky drinkers [17]. However, this study did not examine whether 
drinking behaviour varied by the age of children in the home, and there is limited research examining this question at the population level. A Finnish study found no difference in alcohol consumption rates of parents by age of the child. However, this null effect may be because the age group categories in the study were large (0-6 years and 7-17 years) and so less sensitive to variation [18].

Evidence suggests that becoming a parent is a transitional phase in life, and alcohol consumption may be influenced by this new role. A large majority of women alter their drinking habits once they are trying to conceive or are pregnant [19]. Other than concern for the health of the baby, the fact that it is not socially acceptable to drink while pregnant [20] may be an influencing factor. There has been limited research conducted on the impact of parenthood on fathers' alcohol consumption across time [21], but some research suggests that parenthood may help with recovery from alcohol dependence [22].

Although the results above suggest that adult alcohol consumption may be influenced by becoming parents, little evidence describes the variables that might moderate or mediate this relationship, including the age of the children. Parents' drinking is likely to influence children through descriptive norms (i.e. role modelling of alcohol consumption) and injunctive norms (rules and expectations about alcohol use) [23]. A Dutch study found that normative alcohol use among parents is negatively related to setting rules and guidelines for children around alcohol [24]. The locations where parents drink are also likely to define descriptive norms. As already noted, the majority of alcohol consumed in Australia is consumed within people's homes, particularly for adults aged 25 years and over. In addition to a person's home being the most common place to drink, the level of consumption within the home was high, predominantly a result of the larger number of drinking occasions rather than drinks per session [25]. As parents often have restrictions on their ability to socialise outside the home (e.g. having to arrange for babysitters to care for their children), the present study aimed to investigate whether age of the children impacted parents consumption of alcohol within the home. A Canadian study investigated this and concluded that it may not be the parental role that structures drinking, but the fact that parents (given their parental responsibilities) were restricted in access to bars, discos and hotels, where drinking tends to be heavy [26]. 
This study was designed to: (i) compare alcohol consumption patterns between Australians with and without children; (ii) compare parent consumption between locations; and (iii) determine the impact of age of youngest child in the household. The youngest child was chosen because research has shown that alcohol consumption reduces for women when they are breastfeeding [27], suggesting that this age, and the early years, may be critical.

The following hypotheses were tested:

Hypothesis 1: Parents will be less likely to exceed Australian alcohol guideline thresholds than adults without children;

Hypothesis 2: Fathers will be more likely to exceed Australian alcohol guideline thresholds than mothers;

Hypothesis 3: Mothers whose youngest child is an infant (0-2 years old), will be more likely to abstain than mothers with older children; and

Hypothesis 4: Parents, particularly those with younger children, will be more likely to consume alcohol in the home than adults without children.

\section{METHODS}

\section{Data and procedure}

This paper utilised data collected as part of the 2013 National Drug Strategy Household Survey. The National Drug Strategy Household Survey is undertaken by the Australian Institute of Health and Welfare and assesses illicit and licit drug use in a representative sample of the population aged 12 and above. Households were selected in a multistage, stratified by area, random sample. The study employed a drop-and-collect pen and paper survey. Interviewers made 3 attempts to contact selected households and 3 attempts to personally collect the completed questionnaire. If collection was not possible, a reply-paid addressed envelope was provided. The respondent was selected from members in the household aged 12 years or over on the basis of being the one with the next birthday, and participation was voluntary. For adults aged years 18 and over (relevant to this analysis), a 
completed interview was classified as implied consent. The fieldwork was conducted from 31 July to 1 December 2013. Overall, contact was made with 48,579 households, and 23,855 questionnaires were classified as useable (13,945 refused; 1063 did not speak English; 341 were incapacitated; 9117 did not return the questionnaire or it was un-useable; and a further 258 were coded as other/non-response), yielding a response rate of 49.1\% [28].

Data were weighted by geographical stratification, household size, age and sex based on the age/sex profile of each stratum using the Australian Bureau of Statistics estimated resident population data for June 2012 [29]. The survey methodology were approved by the Australian Institute of Health and Welfare Ethics Committee.

\section{Measures}

Respondents who reported that they were a parent/guardian of at least one dependent child were defined as a 'parent' for the purposes of this paper. Parents who had a dependent child in the household were asked 'of all the dependent children, how many are in each of these age categories? '0-2 years old', '3-5 years old', '6-8 years old', '9-11 years old', '12-14 years old', ' 15 years and over'. Responses were grouped into a variable 'youngest child' using these categories (collapsing 6-8 and 9-11 years old into a primary school category).

Demographic information was collected including respondent's age, gender, and marital status (categorical variable coded into never married, divorced, and married/de facto). Highest educational attainment was coded into completed primary/high school, certificate/diploma, bachelor degree and postgraduate degree. Employment status was coded into currently employed, unemployed/unable to work and other (student, home duties, retired). Three categories were used for the household income, $\$ 1600$ per week or more, \$1000-\$1599 per week and \$999 per week or less. Postcode data were merged with the 2011 Socio-economic Index for Areas, Index of disadvantage to allow analysis by ecological measures of level of disadvantage [30]. 
Respondent's alcohol consumption was assessed using a graduated quantity-frequency measure. In the analyses that follow, alcohol consumption is categorised in terms of the 2009 Australian Guidelines to Reduce Health Risks from Drinking Alcohol [31]. The guideline for reducing alcohol-related harm over a lifetime is 'For healthy men and women drinking no more than two standard drinks on any day' (i.e. averaging no more than two standard drinks per day). The guideline for reducing the risk of injury on a single occasion of drinking is 'For healthy men and women, drinking no more than four standard drinks on a single occasion'. The Australian standard drink contains 10g of alcohol [31]. For the purposes of this paper, respondents were scored as exceeding this guideline on two alternative variables: if they exceeded the guidelines for single occasion risk at least monthly, and if they did it at least weekly. Respondents were also asked 'Where do you usually drink alcohol?' and were asked to mark all that apply from a range of response options (Table 3).

\section{Statistical analysis}

In order to take into account the clustered sampling design of the National Drug Strategy Household Survey, analyses were conducted using StataIC 13.1 (Stat Corp, 2013). SVYSET and SVY commands were used; these estimate test statistics while taking into consideration survey design effects, stratification, weighting and the primary sampling unit. All percentages, chi-square-tests, effect sizes and confidence intervals were population weighted estimates accounting for the clustered survey design. All data were tested for sampling variability and the relative standard errors were all less than $25 \%$. They were therefore considered sufficiently reliable for most purposes by the Australian Institute of Health and Welfare [28].

Drinking rates differ substantially by age, and the vast majority of parents in the current sample fell into the 25-55 year age category (84.1\%). We therefore excluded those aged 1224 years $(n=2900)$ and 56 years and over $(n=9068)$, leaving 11,886 respondents aged $25-55$ years, of whom 11,591 provided their parental and drinking status (64.7\% parents). This allowed for comparisons by parental status without biasing the non-parent sample with the drinking rates of older adults. It also allowed for age-matched comparison of adults with and without children. Logistic regression analyses for males (Table 1) and females (Table 2) with 
the consumption variables: (i) exceeding guidelines for increased lifetime risk on average per day; (ii) exceeding the guidelines for short-term risk at least monthly; and (iii) exceeding the guidelines for short-term risk at least weekly. Model 1 controlled for parental age and Model 2 controlled for parental age, marital and employment status because univariate analysis indicated significant differences on these depending on parental status.

\section{RESULTS}

\section{Sample characteristics}

Demographic characteristics of parents and non-parents indicated that there were significantly more females in the parent group than the non-parent group (53.6\% vs $45.7 \%$; $C$ $(\mathrm{df}=1, \mathrm{~N}=11,591)=50.3, P<0.001)$. Overall, parents were also more likely to be married or in a de-facto relationship $\left(87.3 \%\right.$ vs $\left.55.0 \% ; \mathcal{C}^{2}(\mathrm{df}=1, \mathrm{~N}=11,591)=712.82, P<0.001\right)$ and less likely to be currently employed $(76.2 \%$ vs $79.6 \%$; $C$ ( $(\mathrm{df}=1, \mathrm{~N}=11,591)=16.62, P<$ $0.001)$. Rates of disadvantage, education and household income were equivalent.

\section{Parent versus non-parent alcohol consumption}

It was hypothesised that parents would be less likely to exceed Australian alcohol guideline thresholds than adults without children. Results confirm this hypothesis: fewer Australian parents aged 25-55 years drank in excess of the National Health and Medical Research Council guidelines for lifetime risk of alcohol-related disease and injury (18.2\%, 95\% confidence interval [CI] 17.0-19.4) compared with non-parents $(24.2 \%, 95 \%$ CI 22.6-25.8) $(C \zeta(\mathrm{df}=2, \mathrm{~N}=11,219)=18.83, P<0.001)$. A lower proportion of parents exceeded the guidelines for single-occasion risk on an at least weekly basis $(14.2 \%, 95 \%$ CI 13.2-15.3) compared with non-parents $(21.2 \%, 95 \%$ CI 19.6-22.8) $(C \zeta(\mathrm{df}=2, \mathrm{~N}=11,219)=28.03, P$ $<0.001)$. Furthermore, a lower proportion of parents exceeded the guidelines for singleoccasion risky drinking at least monthly (27.5\%, 95\% CI 26.2-28.9) versus non-parents $(35.9 \%, 95 \%$ CI $34.0-37.8)(\mathcal{C}(\mathrm{df}=2, \mathrm{~N}=11,219)=27.22, P<0.001)$.

The hypothesis that more fathers would exceed the Australian alcohol guideline thresholds than mothers was confirmed, with fathers significantly (Note: lifetime risk: $(\mathcal{C}(\mathrm{df}=5, \mathrm{~N}=$ 
$7025)=153.93, P<0.0001)$; single occasion, monthly: $(\mathcal{C}(\mathrm{df}=2, \mathrm{~N}=7025)=169.96, P<$ $0.0001)$; single occasion, weekly: $(C \zeta(\mathrm{df}=2, \mathrm{~N}=7025)=114.13, P<0.0001))$ more likely to exceed all guidelines. Specifically, fathers exceeded mothers for increased lifetime risk (28.3\%; 95\% CI 26.4-30.3 vs 9.6\%; 95\% CI=8.7-10.7); the single occasion risk of alcoholrelated injury guideline on an at least weekly basis $(22.1 \%$; 95\% CI 20.3-24.0 vs 7.8; 95\% CI 7.0-8.8); and the single occasion risk of alcohol-related injury guideline on an at least monthly basis $(40.0 ; 95 \%$ CI=37.8-42.3 vs $16.9 \%$; 95\% CI 15.7-18.2).

The hypothesis that mothers with children aged 2 years and under would be more likely to abstain than mothers of older children was supported. Figure 1 shows the proportion of nondrinkers and drinkers at different levels, by the age of youngest child in the household and the gender of respondent. There were no significant differences in abstention rates for men by parental status. Among women there was a significantly higher abstention rate for those that had a child in the household aged 2 years and under, than all other groups.

At the univariate level, the relationship between fathers' consumption and age of the youngest child (see Figure 1) had no clear pattern. However, mothers were less likely than non-mothers to exceed the guideline for increased lifetime-risk or for single occasion risk (either at least monthly or weekly) if their youngest child was an infant (aged 0-2 years); in primary school (6-11 years); or in senior high school or older (15 years and over).

[Insert Figure 1 about here]

Model 1 (summarised in Table 1) showed no impact of father status on prevalence of consumption at rates associated with increased lifetime risk. This effect remained after controlling for the fathers' age, employment and marital status in Model 2. By contrast, after controlling for the fathers' age (Model 1), fathers with a youngest child aged 0-2 years were less likely to exceed the guidelines for increased short-term risk on an at least monthly basis than non-fathers. This effect was also found in Model 2 after controlling for fathers' age, employment and marital status. Model 1 indicated that fathers with a child aged 5 years or 
younger were less likely to exceed the guidelines for increased short-term risk on an at least weekly basis than non-fathers, when controlling for fathers' age. This effect remained but only for fathers with the youngest child aged 0-2 years when controlling for fathers' age, employment and marital status in Model 2.

Table 2 shows that, among women, results were very similar across both models. Overall, mothers were less likely to exceed the guideline for increased lifetime risk if their youngest child was an infant (0-2 years); in primary school (6-11 years) and in high school or above (15 years and over) compared with women without children. After controlling for mothers' age, mothers were also less likely to exceed the guideline for short-term risk at least weekly and monthly with the same age-categories of youngest child as above (i.e. 0-2 years, 6-11 years and 15 years and over). However, the effect for mothers of children in primary school (6-11 years) was diminished after controlling for mothers' age, marital and employment status.

[Insert Tables 1 and 2 about here]

\section{Where do parents usually drink alcohol?}

The final hypothesis tested the impact of parenthood on location of consumption and the moderating impact of child age. Results confirmed that overall, parents were significantly more likely to drink in their home $(84.6 \%$ vs $79.6 \%$; $\mathcal{C}(\mathrm{df}=1, \mathrm{~N}=9393)=29.8, P<0.0001)$ and significantly less likely to drink at a friends' house $(38.5 \%$ vs $43.0 \%$; $C$ (df $=1, \mathrm{~N}=$ $9393)=14.32, P<0.001)$, at a party at a friends' house $(31.2 \%$ vs $35.7 \% ; C(d f=1, N=9393)$ $=15.12, P<0.001)$, at restaurants/cafés $(39.0 \%$ vs $45.6 \%$; $C$ C $(\mathrm{df}=1, \mathrm{~N}=9393)=28.07, P$ $<0.0001)$ and at licenced premises $(34.4 \%$ vs $48.2 \%$; $\mathcal{C}(\mathrm{df}=1, \mathrm{~N}=9393)=134.41, P<.0001)$ than adults without children. Table 3 confirms the pattern about drinking in the home, with fathers of children aged 0-2 years or 6-14 years being significantly more likely to drink in the home than non-fathers.

The pattern was less clear among women, there were no significant differences found between mothers and those without children for drinking in the home or drinking a friend's house. However, significantly fewer mothers reported drinking at restaurants and cafes or at 
licenced premises than women without children. There were no significant differences in place of consumption by age of the youngest child in the home among mothers.

[Insert Table 3 about here]

\section{DISCUSSION}

Consistent with our first hypothesis and previous Australian studies, the results confirm that parents are less likely to exceed health guidelines for alcohol consumption than non-parents $[16,17]$. Most importantly, the results highlight how age of the child moderates this result, particularly among mothers.

Also as hypothesised, results indicated that fathers are far more likely to exceed the guideline thresholds than mothers. Overall, abstention rates did not differ among men by parental status or for fathers according to age of child in the home, nor did the proportion of fathers and nonfathers that drank in excess of the guidelines for lifetime risk on an average daily basis. This contrasted with results for mothers, who were more likely to abstain when their child was an infant (aged 0-2 years). A possible factor contributing to this is the widely promulgated Australian recommendation that women who are pregnant and breastfeeding should avoid alcohol [19].

Men were less likely to exceed the guideline for short-term risk either weekly or monthly if they had infants in the household. One possible explanation that warrants further investigation is that fathers may have less opportunity to drink away from home when the children are young. Future research should test motivations for drinking in different environments. 
Among women, an interesting pattern emerged in examination of those exceeding the guidelines for lifetime risk and short-term risk (monthly and weekly). Mothers were significantly less likely than other women to exceed the guideline for increased risk when their youngest child in the household was an infant (i.e. aged 0-2); in primary school (6-11 years) or in senior high school or beyond (15 years and over). They were also less likely to exceed the guideline for increased short-term risk at least monthly or weekly if their child was an infant or in senior high school or beyond. Although the reasons why these ages are associated with more controlled intake remain to be established, perceived role-related responsibilities should be examined. These may include primary parenting responsibility and the challenge of return to work.

A study drawing on Classical Role Theory, posits that the greater the number of roles a person has, the more an individual's life is structured by meaningful activities, and the less likely they will engage in higher volume drinking [32]. It was particularly interesting to note that mothers were less likely to exceed the guidelines, independent of sociodemographic factors, when their youngest dependent child was 15 years or over. The reasons behind this finding require further research including exploring how mothers' perceived responsibilities vary according to the ages of their children and how these perceived responsibilities impact behaviour. This may include potential roles in transporting their adolescents to social engagements and parties and the fact they may see themselves as role models for children entering an age at which they will be increasingly exposed to peer consumption.

Although parents were less likely to exceed alcohol guidelines than non-parents, it is important to highlight that there are still a high number of Australian children with parents who consume alcohol in excess on a regular basis. Results indicated that approximately one in four Australian fathers and one in ten mothers are drinking more than two standard drinks on average per day. Furthermore, one in five fathers are drinking more than four standard drinks on any one occasion at least once per week. This has implications for general parenting, role-modelling and rule setting around alcohol. It is recommended that the drinking of fathers be further examined, particularly within the home, and possible maternal compensation for paternal consumption be tested. 
We also found, as predicted, that parents were more likely to drink alcohol within the home setting than non-parents. On one hand, this is a positive finding, as US evidence shows that drinking at home in comparison to bars is less likely to be associated with heavy drinking and also less likely to be associated with physical abuse of children [33]. On the other hand, this drinking is potentially more likely to occur in front of children, thereby providing negative role modelling and impacting children's alcohol expectancies, initiation and consumption patterns in childhood and adolescence.

The hypothesis that parents would be more likely to consume alcohol in the home if their child was younger, was confirmed among fathers, but not among mothers. Consistent with the finding by Paradis (2011) [26], we found that parents were less likely to drink in other contexts such as restaurants and licenced premises, where heavier consumption is more likely. The results of this study lend some support to the contention that parenting "protects" people from exposure to contexts that encourage consumption.

Although parents were more likely to consume alcohol within the home, it is not clear whether this consumption occurred in front of children. This is important because, as argued by Voogt et al (2017) [34], some parents may drink frequently, but not when their children are present, and others may drink less frequently but may predominantly do so in front of their children. This suggests that children's exposure to parental alcohol use rather than parental alcohol use per se, may be more important to role modelling. A recent systematic review has confirmed that alcohol expectancies predict alcohol use initiation and drinking patterns over time in children and adolescents [35]. Further research is important to determine whether parents are aware of their impact as a role model on their child's drinking behaviour and alcohol-related cognitions (i.e. knowledge, norms and expectancies) that have been shown to influence initiation and consumption patterns $[35,36]$.

This study, while one of the largest in Australia, has some limitations. First, this study investigated the impact on parents' consumption of children and the moderating impact of child age. Although parent gender was important, data did not allow testing for the impact of child gender. Second, analyses were focussed on the youngest child and did not take into 
account age or number of the other children in the household. Third, it is possible that parents may be differentially subject to social desirability bias in responding to these questions. Fourth, this study did not examine the impact of single parenting on consumption and lastly, the response rate of $49 \%$, although similar to previous surveys [37], means that data may not be generalisable.

Despite these limitations, the findings have important implications for public health. Parents are less likely to exceed recommended alcohol consumption guidelines, but there is still a significant minority, particularly fathers, who are drinking at levels that warrant further attention. A focus on adult drinking is important in public health efforts to reduce population drinking rates, and an important element of this, is attention to levels of consumption in adults in the age groups where parents with children at home are in the majority.

\section{Acknowledgements}

We would like to thank the Australian Institute of Health and Welfare who manage the National Drug Strategy Household Survey and the Australian Data Archive for facilitating our access to the data. 


\section{References}

1. World Health Organization. Global status report on alcohol and health 2014 Geneva: World Health Organization; 2014 [Available from: www.who.int/substance_abuse/publications/global_alcohol_report/en/

2. Australian Institute of Health and Welfare (AIHW). National Drug Strategy Household Survey (NDSHS) 2016 - key findings. Canberra: AIHW; 2017 [Available from: www.aihw.gov.au/reports/illicit-use-of-drugs/ndshs-2016-keyfindings/contents/summary.

3. Foundation for Alcohol Research and Education. Annual alcohol poll 2018 - Attitudes \& behaviours. Canberra: FARE; 2018.

4. Australian Institute of Health and Welfare. National drug strategy household survey 2016. Detailed findings. Canberra: AIHW; 2017.

5. Bandura A. Social learning theory. Envlewood Cliffs, N.J.: Prentice Hall; 1977.

6. Getz JG, Bray JH. Predicting heavy alcohol use among adolescents. Am J Orthopsychiatry 2005;75:102-16.

7. Hawkins JD, Graham JW, Maguin E, Abbott R, Hill KG, Catalano RF. Exploring the effects of age of alcohol use initiation and psychosocial risk factors on subsequent alcohol misuse. J Stud Alcohol 1997;58:280-90.

8. Peterson PL, Hawkins JD, Abbott RD, Catalano RF. Disentangling the effects of parental drinking, family management, and parental alcohol norms on current drinking by black and white adolescents. J Res Adolesc 1994;4:203-27.

9. Ryan SM, Jorm AF, Lubman DI. Parenting factors associated with reduced adolescent alcohol use: A systematic review of longitudinal studies. Aust N Z J Psychiatry 2010;44:774-83.

10. Latendresse SJ, Rose RJ, Viken RJ, Pulkkinen L, Kaprio J, Dick DM. Parenting mechanisms in links between parents' and adolescents' alcohol use behaviors. Alcohol Clin Exp Res 2008;32:322-30.

11. Seljamo S, Aromaa M, Koivusilta L, Rautava P, Sourander A, Helenius H, et al. Alcohol use in families: A 15-year prospective follow-up study. Addiction 2006;101:984-92.

12. Windle M. Parental, sibling, and peer influences on adolescent substance use and alcohol problems. Appl Dev Sci 2000;4:98-110.

13. Engels RCME, Knibbe RA, Vries HD, Drop MJ, van Breukelen GJP. Influences of parental and best friends' smoking and drinking on adolescent use: A longitudinal study. J Appl Soc Psychol 1999;29:337-61. 
14. Mokdad AH, Forouzanfar MH, Daoud F, Mokdad AA, El Bcheraoui C, Moradi-Lakeh $\mathrm{M}$, et al. Global burden of diseases, injuries, and risk factors for young people's health during 1990-2013: a systematic analysis for the Global Burden of Disease Study 2013. Lancet 2016;387:2383-401.

15. Hingson RW, Heeren T, Winter MR. Age at drinking onset and alcohol dependence: age at onset, duration, and severity. Arch Pediatr Adolesc Med 2006;160:739-46.

16. Maloney E, Hutchinson D, Burns L, Mattick R. Prevalence and patterns of problematic alcohol use among Australian parents. Aust N Z J Public Health 2010;34:495-501.

17. Laslett A, Jiang H, Room R. Alcohol consumption of Australian parents: Continuity and change in the new millennium. Centre for Alcohol Policy Research; 2017.

18. Raitasalo K, Holmila M, Mäkelä P. Drinking in the presence of underage children: Attitudes and behaviour. Addict Res Theory 2011;19:394-401.

19. Callinan S. Alcohol consumption during pregnancy: Results from the 2010 National Drug Strategy Household Survey. Centre for Alcohol Policy Research; 2012.

20. Woodward LJ, Fergusson DM, Horwood LJ. Gender differences in the transition to early parenthood. Dev Psychopathol 2006;18:275-94.

21. Little M, Handley E, Leuthe E, Chassin L. The impact of parenthood on alcohol consumption trajectories: variations as a function of timing of parenthood, familial alcoholism, and gender. Dev Psychopathol 2009;21:661-82.

22. Dawson DA, Grant BF, Stinson FS, Chou PS. Maturing out of alcohol dependence: the impact of transitional life events. J Stud Alcohol 2006;67:195-203.

23. Mares SH, van der Vorst H, Engels RC, Lichtwarck-Aschoff A. Parental alcohol use, alcohol-related problems, and alcohol-specific attitudes, alcohol-specific communication, and adolescent excessive alcohol use and alcohol-related problems: An indirect path model. Addict Behav 2011;36:209-16.

24. Spijkerman R, van den Eijnden RJ, Huiberts A. Socioeconomic differences in alcoholspecific parenting practices and adolescents' drinking patterns. Eur Addict Res 2008;14:26-37.

25. Callinan S, Livingston M, Room R, Dietze P. Drinking contexts and alcohol consumption: How much alcohol is consumed in different Australian locations? J Stud Alcohol Drugs 2016;77:612-9.

26. Paradis C. Parenthood, drinking locations and heavy drinking. Soc Sci Med 2011;72:1258-65. 
27. Wilson J, Tay RY, McCormack C, Allsop S, Najman J, Burns L, et al. Alcohol consumption by breastfeeding mothers: Frequency, correlates and infant outcomes. Drug Alcohol Rev 2017;36:667-76.

28. Australian Institute of Health and Welfare. National Drug Strategy Household Survey detailed report 2013. Canberra: AIHW; 2014

29. Australian Bureau of Statistics. Australian Demographic Statistics, Jun 2012. Canberra: ABS; 2012.

30. Pink B. Socio-Economic Indexes for Areas (SEIFA). Canberra: Australian Bureau of Statistics; 2011.

31. National Health and Medical Research Council. Australian Guidelines to Reduce Health Risks from Drinking Alcohol. Canberra: Commonwealth of Australia.; 2009.

32. Kuntsche S, Knibbe RA, Gmel G. Social roles and alcohol consumption: a study of 10 industrialised countries. Soc Sci Med 2009;68:1263-70.

33. Freisthler B, Gruenewald PJ. Where the individual meets the ecological: a study of parent drinking patterns, alcohol outlets, and child physical abuse. Alcohol Clin Exp Res 2013;37:993-1000.

34. Voogt C, Beusink M, Kleinjan M, Otten R, Engels R, Smit K, et al. Alcohol-related cognitions in children (aged 2-10) and how they are shaped by parental alcohol use: A systematic review. Drug Alcohol Depend 2017;177:277-90.

35. Smit K, Voogt C, Hiemstra M, Kleinjan M, Otten R, Kuntsche E. Development of alcohol expectancies and early alcohol use in children and adolescents: A systematic review. Clin Psychol Rev 2018;60:136-46.

36. Yap MBH, Cheong TWK, Zaravinos-Tsakos F, Lubman DI, Jorm AF. Modifiable parenting factors associated with adolescent alcohol misuse: A systematic review and meta-analysis of longitudinal studies. Addiction 2017;112:1142-62.

37. Australian Institute of Health and Welfare. National Drug Strategy Household Survey: About Our Data Canberra: AIHW; 2018 [6 July 2018]. Available from: www.aihw.gov.au/about-our-data/our-data-collections/national-drug-strategy-householdsurvey. 
60

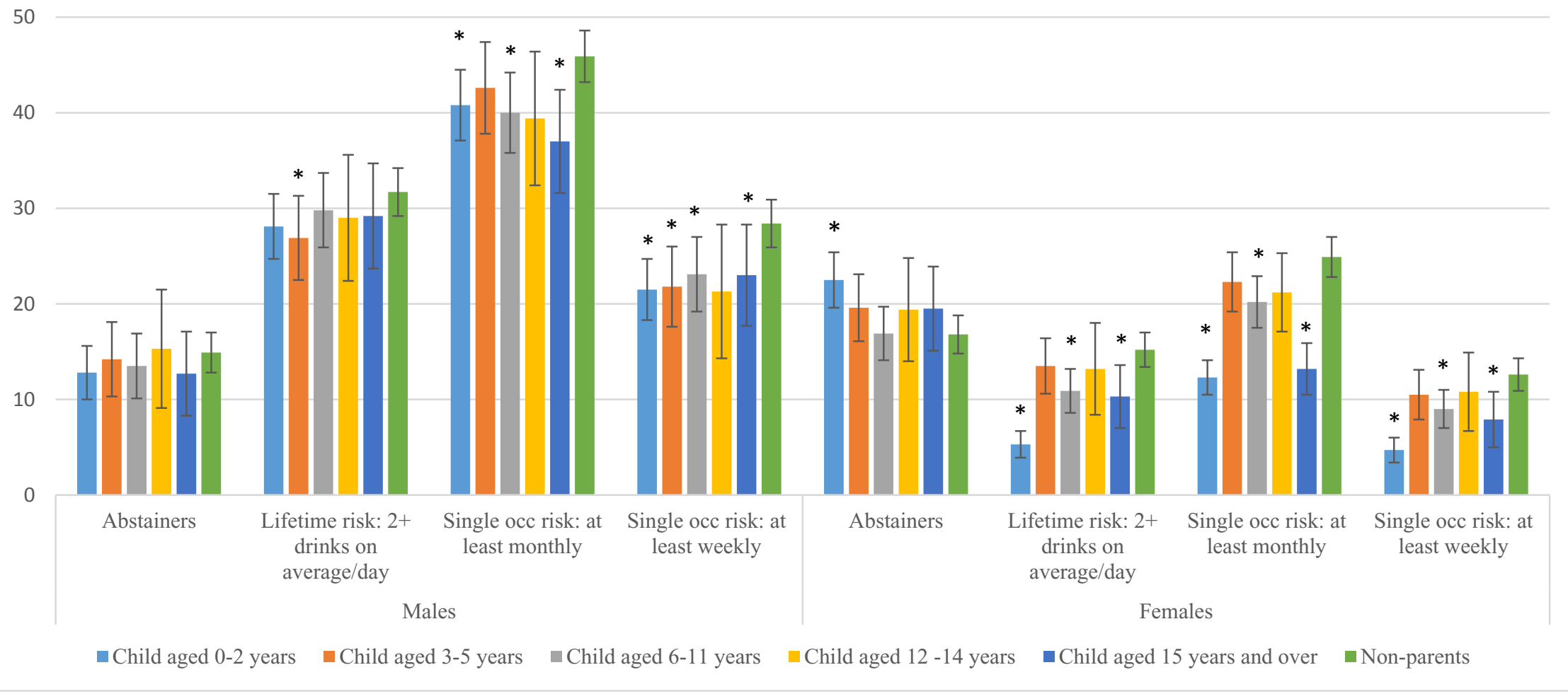

Figure 1: Prevalence (\%) of alcohol consumption among adults aged $25-55$ years by age of youngest child. $* P<0.05$ chi-square between group and non-parents. 
This article is protected by copyright. All rights reserved. 
Table 1. Logistic regression analysis: exceeding guidelines among males aged 25-55 by age of youngest child in the house

\begin{tabular}{|c|c|c|c|c|}
\hline & $\begin{array}{l}\text { Model } 1 \\
\text { OR } \\
n=4847\end{array}$ & $95 \% \mathrm{CI}$ & $\begin{array}{l}\text { Model } 2 \\
\text { OR } \\
n=4638\end{array}$ & $95 \% \mathrm{CI}$ \\
\hline \multicolumn{5}{|c|}{ 1. Exceeding the guidelines for lifetime risk of disease or injury } \\
\hline \multicolumn{5}{|c|}{ Age of youngest child (no child as ref category) } \\
\hline Child aged $0-2$ years & 0.84 & $0.68-1.02$ & 0.85 & $0.67-1.06$ \\
\hline Child aged 3-5 years & 0.80 & $0.63-1.02$ & 0.86 & $0.66-1.11$ \\
\hline Child aged 6-11 years & 0.94 & $0.77-1.16$ & 0.96 & $0.77-1.20$ \\
\hline Child aged $12-14$ years & 0.92 & $0.66-1.28$ & 0.93 & $0.66-1.32$ \\
\hline Child aged 15 years and over & 0.94 & $0.71-1.24$ & 0.99 & $0.74-1.31$ \\
\hline Age (continuous variable) & 1.00 & $0.99-1.00$ & 0.99 & $0.98-1.00$ \\
\hline \multicolumn{5}{|c|}{ Employment status (employed as ref category) } \\
\hline Unemployed & & & 1.01 & $0.71-1.43$ \\
\hline Other & & & $0.51 * * *$ & $0.37-0.69$ \\
\hline \multicolumn{5}{|c|}{ Marital status (never married as ref category) } \\
\hline Divorced & & & $1.41 *$ & $1.04-1.91$ \\
\hline Married/de facto & & & 0.87 & $0.70-1.09$ \\
\hline
\end{tabular}

\section{Exceeding the guidelines for short-term risk on a monthly basis} Age of youngest child (no child as ref category)

$\begin{array}{lllll}\text { Child aged 0-2 years } & \mathbf{0 . 7 8}^{*} & 0.65-0.94 & \mathbf{0 . 7 7 *} & 0.62-0.94 \\ \text { Child aged 3-5 years } & 0.89 & 0.70-1.12 & 0.90 & 0.70-1.16 \\ \text { Child aged 6-11 years } & 0.87 & 0.71-1.08 & 0.85 & 0.68-1.07 \\ \text { Child aged 12-14 years } & 0.91 & 0.66-1.26 & 0.90 & 0.64-1.25 \\ \text { Child aged 15 years and over } & 0.83 & 0.64-1.09 & 0.82 & 0.63-1.07 \\ \text { Age (continuous variable) } & \mathbf{0 . 9 8 * * *} & 0.97-0.99 & \mathbf{0 . 9 8} * * * & 0.97-0.99\end{array}$

Employment status (employed as ref category)

Unemployed

$\begin{array}{ll}0.76 & 0.55-1.04 \\ \mathbf{0 . 4 5 * * *} & 0.34-0.59\end{array}$

Other

$1.19 \quad 0.88-1.62$

Marital status (never married as ref category)

$0.84 \quad 0.68-1.04$

3. Exceeding the guidelines for short-term risk on a weekly basis

Age of youngest child (no child as ref category)

Child aged $0-2$ years

0.67*** $0.54-0.84$

$0.71 * *$

$0.56-0.92$

Child aged 3-5 years

0.71* $0.55-0.92$

0.79

$0.60-1.04$

Child aged 6-11 years

$0.82 \quad 0.65-1.04$

0.85

$0.66-1.10$

Child aged $12-14$ years

0.77

$0.51-1.16$

0.82

$0.54-1.25$

Child aged 15 years and over

0.86

$0.63-1.17$

0.92

$0.67-1.25$

Age (continuous variable)

0.99** 0.98-0.99

0.99*

$0.98-1.00$

Employment status (employed as ref category)

Unemployed

$0.92 \quad 0.65-1.32$

Other

Marital status (never married as ref category)

Divorced

$\mathbf{0 . 5 1} * * * \quad 0.37-0.71$

Married/de facto

$1.36 \quad 0.98-1.88$

$0.79 *$

0.63-0.99

***P $0.001, * * P \mathrm{~d} 0.01, * P<0.05$ All models were a good fit based on the method by Archer,

Lemeshow (Archer K, Lemeshow S, Hosmer D. Goodness-of-fit tests for logistic regression 
models when data are collected using a complex sampling design. Compu Stat Data Anal 2007;51:4450-64). CI, confidence interval; OR, odds ratio.

This article is protected by copyright. All rights reserved. 
Table 2. Logistic regression analysis: exceeding guidelines among females aged 25-55 by age of youngest child in the house

\begin{tabular}{|c|c|c|c|c|}
\hline & $\begin{array}{l}\text { Model } 1 \\
\text { OR } \\
n=6744\end{array}$ & $95 \% \mathrm{CI}$ & $\begin{array}{l}\text { Model } 2^{\#} \\
\text { OR } \\
n=6414\end{array}$ & $95 \% \mathrm{CI}$ \\
\hline \multicolumn{5}{|c|}{ 1. Exceeding the guidelines for lifetime risk of disease or injury } \\
\hline \multicolumn{5}{|c|}{ Age of youngest child (no child as ref category) } \\
\hline Child aged $0-2$ years & $0.32 * * *$ & $0.24-0.43$ & $0.37 * * *$ & $0.27-0.51$ \\
\hline Child aged $3-5$ years & 0.89 & $0.68-1.16$ & 1.03 & $0.78-1.36$ \\
\hline Child aged 6-11 years & $0.68 * *$ & $0.53-0.88$ & $0.72 *$ & $0.55-0.94$ \\
\hline Child aged $12-14$ years & 0.84 & $0.56-1.26$ & 0.83 & $0.56-1.25$ \\
\hline Child aged 15 years and over & $0.62 * *$ & $0.45-0.87$ & $0.62 * *$ & $0.44-0.87$ \\
\hline Age (continuous variable) & 1.00 & $0.99-1.01$ & 1.01 & $0.99-1.02$ \\
\hline \multicolumn{5}{|c|}{ Employment status (employed as ref category) } \\
\hline Unemployed & & & 0.75 & $0.51-1.09$ \\
\hline Other & & & 0.92 & $0.74-1.13$ \\
\hline \multicolumn{5}{|c|}{ Marital status (never married as ref category) } \\
\hline Divorced & & & 0.99 & $0.71-1.38$ \\
\hline Married/de facto & & & $0.69 * *$ & $0.54-0.88$ \\
\hline
\end{tabular}

\section{Exceeding the guidelines for short-term risk on a monthly basis}

Age of youngest child (no child as ref category)

$\begin{array}{lllll}\text { Child aged 0-2 years } & \mathbf{0 . 3 7} * * * & 0.29-0.46 & \mathbf{0 . 5 0} * * * & 0.39-0.65 \\ \text { Child aged 3-5 years } & 0.83 & 0.66-1.03 & 1.08 & 0.85-1.37 \\ \text { Child aged 6-11 years } & \mathbf{0 . 8 1} * & 0.66-1.00 & 0.96 & 0.78-1.20 \\ \text { Child aged 12-14 years } & 0.97 & 0.72-1.29 & 1.11 & 0.82-1.50 \\ \text { Child aged 15 years and over } & \mathbf{0 . 6 0} * * * & 0.45-0.79 & \mathbf{0 . 6 0} * * * & 0.44-0.81 \\ \text { Age (continuous } \text { variable) } & \mathbf{0 . 9 7} * * * & 0.96-0.98 & \mathbf{0 . 9 8} * * * & 0.97-0.99\end{array}$

Employment status (employed as ref category)

Unemployed

$\begin{array}{ll}\mathbf{0 . 5 5} * * * & 0.39-0.76 \\ \mathbf{0 . 7 8} * * & 0.67-0.92\end{array}$

Other

Marital status (never married as ref category)

Divorced

$0.88 \quad 0.67-1.15$

Married/de facto

$\mathbf{0 . 5 1} * * * \quad 0.43-0.62$

3. Exceeding the guidelines for short-term risk on a weekly basis

Age of youngest child (no child as ref category)

Child aged $0-2$ years

Child aged 3-5 years

$\mathbf{0 . 3 2} * * * \quad 0.23-0.44$

$0.41 * * *$

$0.29-0.58$

Child aged 6-11 years

$0.78 \quad 0.58-1.05$

0.99

$0.72-1.36$

Child aged 12-14 years

0.69** $\quad 0.53-0.90$

0.77

$0.58-1.03$

Child aged 15 years and over

$0.88 \quad 0.58-1.32$

1.06

$0.70-1.62$

Age (continuous variable)

0.63* $0.44-0.92$

0.63 *

0.42-0.94

0.99

$0.98-1.00$

1.00

$0.98-1.01$

Employment status (employed as ref category)

Unemployed

0.81

$0.53-1.22$

Other

0.96

$0.77-1.21$

Marital status (never married as ref category)

Divorced

0.80

$0.56-1.13$

Married/de facto

$\mathbf{0 . 5 0} * * * \quad 0.39-0.65$

***pd0.001, **pd0.01, ${ }^{*} \mathrm{p}<0.05$ All models were a good fit based on the method by Archer, Lemeshow (Archer K, Lemeshow S, Hosmer D. Goodness-of-fit tests for logistic regression 
models when data are collected using a complex sampling design. Compu Stat Data Anal 2007;51:4450-64). CI, confidence interval; OR, odds ratio.

This article is protected by copyright. All rights reserved. 
Table 3. Place of consumption among adults aged 25-55 years by gender of the parent/adult and age of youngest child among parents

\begin{tabular}{|c|c|c|c|c|c|c|c|}
\hline Response categories & $\begin{array}{l}\text { Child aged } \\
\text { 0-2 years } \\
(95 \% \mathrm{CI}) \\
\end{array}$ & $\begin{array}{l}\text { Child aged } \\
3-5 \text { years } \\
(95 \% \mathrm{CI}) \\
\end{array}$ & $\begin{array}{l}\text { Child aged } \\
\text { 6-11 years } \\
(95 \% \mathrm{CI}) \\
\end{array}$ & $\begin{array}{c}\text { Child aged } \\
12-14 \text { years } \\
(95 \% \text { CI }) \\
\end{array}$ & $\begin{array}{l}\text { Child aged } \\
15+\text { years } \\
(95 \% \mathrm{CI}) \\
\end{array}$ & $\begin{array}{l}\text { No } \\
\text { dependent } \\
\text { children } \\
(95 \% \mathrm{CI}) \\
\end{array}$ & $\begin{array}{l}\text { Summary } \\
\text { chi-square } \\
\text { significance }\end{array}$ \\
\hline \multicolumn{8}{|l|}{ Males } \\
\hline \multicolumn{8}{|l|}{$\begin{array}{l}\text { Where do you usually drink } \\
\text { alcohol? }\end{array}$} \\
\hline $\begin{array}{l}\text { In my own/spouse's/ } \\
\text { partner's home }\end{array}$ & $87.8(85.0-90.2)$ & $81.7(76.6-85.8)$ & $86.3(82.8-89.1)$ & $90.3(85.0-93.8)$ & $84.1(79.1-88.1)$ & $79.3(77.0-81.4)$ & $P<0.001$ \\
\hline $\begin{array}{l}\text { A party at someone's } \\
\text { house }\end{array}$ & $28.2(24.9-31.7)$ & $26.7(22.3-31.6)$ & $30.7(26.6-35.2)$ & $30.9(24.0-38.7)$ & $26.2(21.2-31.8)$ & $35.2(32.5-38.0)$ & $P<0.01$ \\
\hline At restaurants/cafes & $35.8(32.2-39.7)$ & $29.0(24.3-34.1)$ & $36.0(31.6-40.7)$ & $37.8(30.7-45.6)$ & $35.1(29.3-41.3)$ & $40.1(37.3-42.9)$ & $P<0.05$ \\
\hline $\begin{array}{l}\text { At licenced premises (e.g. } \\
\text { pubs, clubs) }\end{array}$ & $38.9(35.2-42.8)$ & $34.9(29.8-40.4)$ & $33.4(29.0-38.0)$ & $38.8(31.4-46.7)$ & $34.3(28.6-40.5)$ & $50.3(47.5-53.1)$ & $P<0.001$ \\
\hline \multicolumn{8}{|l|}{ Females } \\
\hline \multicolumn{8}{|l|}{$\begin{array}{l}\text { Where do you usually drink } \\
\text { alcohol? }\end{array}$} \\
\hline At a friend's house & $40.6(37.5-43.8)$ & $39.2(35.2-43.3)$ & $42.8(35.2-43.3)$ & $38.3(32.3-44.6)$ & $36.1(31.1-41.4)$ & $43.2(40.7-45.8)$ & NS \\
\hline A party at someone's & $32.2(29.1-35.4)$ & $32.2(28.4-36.2)$ & $34.7(31.2-38.2)$ & $37.9(31.9-44.3)$ & $35.5(30.5-40.9)$ & $36.4(34.0-38.8)$ & NS \\
\hline & $43.5(40.3-46.9)$ & $39.3(35.2-43.6)$ & $45.0(41.2-48.9)$ & $42.8(36.5-49.5)$ & $43.7(38.6-49.1)$ & $52.3(49.7-54.8)$ & $P<0.001$ \\
\hline $\begin{array}{l}\text { At restaurants/cafes } \\
\text { At licenced premises (e.g. } \\
\text { pubs, clubs) }\end{array}$ & $33.0(29.9-36.3)$ & $34.3(30.4-38.4)$ & $32.4(29.2-35.8)$ & $32.6(26.7-39.0)$ & $30.0(25.3-35.3)$ & $45.8(43.2-48.3)$ & $P<0.001$ \\
\hline
\end{tabular}

This article is protected by copyright. All rights reserved. 
CI, confidence interval; NS, not significant.

This article is protected by copyright. All rights reserved. 


\section{University Library}

\section{- M M N E R VA A gateway to Melbourne's research publications}

Minerva Access is the Institutional Repository of The University of Melbourne

Author/s:

Bowden, JA;Delfabbro, P;Room, R;Miller, C;Wilson, C

Title:

Parental drinking in Australia: Does the age of children in the home matter?

Date:

2019-03

Citation:

Bowden, J. A., Delfabbro, P., Room, R., Miller, C. \& Wilson, C. (2019). Parental drinking in Australia: Does the age of children in the home matter?. Drug Alcohol Rev, 38 (3), pp.306-315. https://doi.org/10.1111/dar.12875.

Persistent Link:

http://hdl.handle.net/11343/284946 